\title{
Globalización y fragmentación territorial. El caso de la región del istmo oaxaqueño
}

\author{
Globalization and territorial fragmentation. \\ The case of the Oaxacan isthmus region
}

\section{Carlos García Medina *}

\begin{abstract}
Resumen
El desarrollo del capitalismo ha traído consigo una nueva configuración espacial del mundo en diferentes aspectos: económicos, políticos, sociales y culturales, ya sea a nivel internacional, nacional, regional y local. Aunque este auge capitalista es muy distinto de país a país o de región a región, repercute de una manera o de otra en las naciones del mundo, las cuales se relacionan cada vez más, directamente o indirectamente. Algunas localidades del mundo en desarrollo toman relevancia a nivel mundial, debido a la riqueza de sus materias primas, a la extracción de sus recursos naturales, mano de obra barata, entre otros aspectos; en estos nuevos espacios se ubican grandes inversiones extranjeras, que van provocado una fragmentación espacial a nivel local, regional, nacional e internacional; un ejemplo de ello, es el caso del Estado de Oaxaca, México, región del istmo oaxaqueño. Para entender dicho proceso, es necesario comprender la globalización actual en el mundo y su relación con los países en desarrollo, México y el estado de Oaxaca.
\end{abstract}

\section{Palabras clave}

Oaxaca, Globalización, fragmentación territorial, región del istmo oaxaqueño México.

\begin{abstract}
The expansion of capitalism has caused the spatial re-configuration of the world in economic, political, social and cultural spheres at local, regional, national and international levels. Although capitalism varies from country to country and from region to region, it impacts all countries-which are increasingly interrelated-directly or indirectly. Some areas in the developing world have gained global importance because of an abundance of raw materials, natural resources extraction, cheap labour costs, among other factors. The level of foreign investment is high in these new spaces and it has caused spatial fragmentation at local, regional, national and international levels. The Oaxacan isthmus region in the state of Oaxaca, Mexico is a case in point. To understand this process, one must understand the current process of globalization and its connection with developing countries, Mexico and the state of Oaxaca.
\end{abstract}

\section{Key words}

Globalization, territorial fragmentation, Oaxacan Isthmus region, Oaxaca, Mexico.

Forma sugerida de citar: GARCÍA MEDINA, Carlos (2012). "Globalización y fragmentación territorial. El caso de la región del istmo oaxaqueño", en: Universitas, X (17), julio-diciembre, pp. 89-99. Quito: Editorial Abya-Yala.

* $\quad$ Profesor de la Universidad del Istmo, Campus Ixtepec, Oaxaca, México, Adscrito a la Licenciatura de Administración Pública. 


\section{Lo global y lo local}

Una característica del nuevo capitalismo es la unificación del mercado mundial, que va acompañado de procesos de privatización y de modernización tecnológica. "Como consecuencia de ello el capitalismo abarcará prácticamente al mundo entero, imponiendo su dinámica territorial de desarrollo desigual e inclusión-exclusión" (Dabat, 2002: 77). Es decir, se transforma la vida social de los pueblos los cuales están conectados a través de las telecomunicaciones a nivel internacional en momentos reales. La llamada crisis económica mundial provoca que los gobiernos tomen soluciones que afectan sobre todo a su población, y no a las empresas transnacionales.

En Europa los gobiernos han adoptado las siguientes medidas: 1. Adelgazamiento del gasto público; 2. Limitaciones salariales y disminución de prestaciones sociales a los trabajadores; 3 . Eliminación de subsidios a diferentes sectores de la economía; 4. Privatización de las empresas gubernamentales; 5. Apoyo a la empresa privada nacional y extranjera (Sterling, 2005: 43-44). Medidas que en Europa han encontrado rechazo por parte de los sindicatos, de los trabajadores y de los estudiantes. Es decir, derechos sociales que la población había logrado conquistar a finales del siglo XIX y principios del XX.

El día 29 de septiembre de 2010 se leía en los principales periódicos europeos la siguiente noticia. "La 'euromanisfestación' convoca a unas 90.000 personas en Bruselas" (Lora, 2010). Dicha capital ha tenido cortes de tráfico vehicular y de metro en la 'Jornada Europa de Acción' unidas las organizaciones de trabajadores de 30 países bajo la Confederación Europea de Sindicatos.

Ante tal situación, los empresarios capitalistas buscan nuevos mercados para invertir y obtener ganancias, dicha inversión se destina principalmente a dos zonas: por un lado, su inversión se concentra en las grandes ciudades donde el mercado es mayor por la abundancia de consumidores y de mano de obra calificada; sin embargo, en los últimos años en las grandes ciudades la población ha tomado conciencia de su desarrollo histórico y de sus derechos como trabajadores; los empleados buscan que se les pague lo justo y que las hora de trabajo se ajusten a las normas laborales del país; por tal motivo, las grandes empresas sobre todo multinacionales y trasnacionales buscan invertir en países donde las normas no se cumplen o donde existe poco conocimiento a cerca de las leyes del país, ya que lo que se busca es optimizar las ganancias sin tener problemas con la población receptora, como está sucediendo en Europa. Lo 
más conveniente es invertir en países en desarrollo, en donde gran parte de la población desconoce sus propias leyes o muchas veces son letra muerta. Estas empresas como slogan enarbolan la ayuda para el progreso y su frase favorita es "desarrollo local"; por lo tanto buscan zonas poco "atractivas" para la inversión, es decir, buscan áreas que se han caracterizado por estar relegadas de las políticas de desarrollo de sus propios países. Como sucede en América Latina, en el Continente Africano y en el Continente Asiático.

Esta nueva forma de capitalismo ha sido observada por intelectuales, organizaciones gubernamentales, organizaciones campesinas, organizaciones obreras que se oponen a la inversión de estas empresas en sus territorios; muchas veces la información de proyectos o programas que se van a realizar entre el gobierno receptor y las empresas multinacionales y nacionales no es aceptada por la población local, o no existe un claro conocimiento de lo que se desea hacer provoca un rechazo. En caso de ser aceptado el proyecto por parte del gobierno beneficiario, lo primero que se observa, por lo regular, es la construcción de carreteras por parte de las empresas extranjeras, también pueden ser puentes, servicios etc., los cuales primeramente serán utilizados por las empresas que están invirtiendo en el lugar, con el fin de transportar sus herramientas que son básicas para la producción y que al fin del proceso redituará en beneficio de la empresa. Bajo este escenario los gobiernos locales, sobre todo en los países en desarrollo, se encuentran en una disyuntiva, ya que los problemas sociales de la población no están resueltos, es decir, faltan servicios básicos como empleo, educación, salud, ingreso, vivienda, agua potable, alcantarillado etc., y estas carencias no las pueden resolver sin la "ayuda" de los países en desarrollo o sin su inversión.

Por lo tanto a los gobiernos receptores se les cuestiona su desarrollo y se les condiciona para recibir los apoyos de el Banco Mundial, de el Fondo Monetario Internacional, de el Banco Interamericano de Desarrollo, entre otras instituciones que financian el desarrollo y a su vez dictan las directrices de las políticas de estos países, con la condición de que si no son acatadas no recibirán la ayuda requerida. Bajo este escenario el Estado otorga beneficios a empresas multinacionales y trasnacionales, aunque se le cuestione su soberanía o su consolidación como Estado, llamándolos en ocasiones erróneamente "crisis de Estado", es decir, ocultando la realidad impuesta por la globalización, la cual ocasiona que los Estados inmersos en ella queden dependientes de las decisiones de los países desarrollados, sin atender prioridades de la sociedad local. 


\section{Fragmentación y globalización}

La restructuración del mundo conlleva que algunas zonas de los países en desarrollo literalmente "desaparezcan del mapa mundial", porque han dejado de tener importancia para los países desarrollados o para empresas trasnacionales, ya que se encuentran sumergidos en una serie de procesos, los cuales tienen diversos orígenes por ejemplo:

Sea por la escasez de sus recursos naturales, sea por el analfabetismo y bajo nivel de instrucción de sus habitantes, sea por largas contiendas bélicas sin visos de solución que en algunos países se dan; lo cierto es que, en efecto, estos espacios han dejado de ser útiles al sistema económico y político internacional. Son simplemente irrelevantes. No importan para nada, ni interesan a nadie, como no sea a algún periodista que consiga recordar de vez en cuando a la opinión pública su existencia, o alguna organización humanitaria, si no ha sido ahuyentada de la zona. Sus territorios y personas, desconectados y marginados de un sistema mundo, cada vez más segmentado en estratos espaciales absolutamente distanciados unos a otros, en todos los sentidos (Romero y Nogué, 2004: 104).

Sin embargo, esto no quiere decir que los territorios estén olvidados, pues una vez que se regeneren los recursos naturales, se pueden aprovechar nuevamente o se pueden realizar obras para acelerar su regeneración. Por otro lado, algunas tierras incógnitas están resurgiendo al mundo globalizado, con sus recursos naturales, con mano de obra barata, infraestructura, instituciones locales, etc., en pocas palabras, con ventajas productivas que ofrece el territorio como es el caso de la región del istmo oaxaqueño. Con apoyos del Banco Mundial, del Fondo Monetario Internacional, la Organización Mundial del Comercio, del Banco Interamericano de Desarrollo y otros; se impulsa el desarrollo neoliberal en el mundo, lo cual debilita la capacidad de los gobiernos locales de tomar sus propias decisiones con respecto a las políticas sociales y económicas. Estas políticas públicas exógenas van con la finalidad de repercutir en determinadas zonas productivas y de alta rentabilidad para la inversión extranjera. Provocando como consecuencia una fragmentación espacial en los territorios, en donde se puede notar el desarrollo impulsado por el capital extranjero y donde se puede observar el desarrollo local impulsado por el país de origen. 


\section{Proceso de globalización en México}

El proceso de globalización en México ha repercutido de manera desigual en las nueve regiones económicas, que lo constituyen, ya que dificulta impulsar a los diferentes actores políticos, sociales, económicos y culturales que compiten con la participación de actores trasnacionales, los cuales cuentan con el apoyo de organizaciones como el Banco Mundial, el Fondo Monetario Internacional, el Banco Interamericano de Desarrollo entre otras instituciones.

En México la globalización ha repercutido en la integración nacional de los territorios, ya que se han marcado aun más los desequilibrios territoriales que existen entre las regiones ganadoras y perdedoras, como es el caso de la región sur.

Las regiones económicas en que se divide el país de México según Ángel Bassols Batalla (1980) son: Noroeste, Norte, Noroeste, Centro-norte, Centrooccidente, Centro-este, Este, Sur y Península de Yucatán, es decir, nueve en total. El estado de Oaxaca se encuentra localizado en la región sur, junto con los estados de Guerrero y Chiapas. Esta región presenta características muy bien marcadas; por ejemplo, en el relieve la región se caracteriza por ser muy desigual: cuenta con cadenas montañosas, valles, depresiones, lagunas, planicie costera; lo que contribuye a sus diferentes climas y diferentes tipos de suelos, los cuales a su vez determinan el tipo de vegetación que predomina en la zona.

Esta región es rica en diversidad cultural, ya que desde antes que llegaron los españoles habitaban en ella varios pueblos indígenas, los cuales han contribuido con su cultura al desarrollo del país; sin embargo, se caracteriza por ser una región con poco desarrollo desde varios puntos de vista. Por ejemplo, en los años de 1990 a 1995 (Plan Puebla Panamá, 2001) la región tenía tasas de crecimiento menores al promedio nacional, debido principalmente a la migración; se tienen elevadas tasas de fecundidad debido a que la población vive en condiciones de atraso y marginación social; la población de la tercera edad es superior al promedio regional y nacional; la tasa de participación de la población económica activa (PEA) en la región son menores del 50\%, las actividades predominantes en la región son las primarias de subsistencia, es decir, la agricultura, ganadería y pesca; con respecto a los profesionales su nivel de ingreso está por debajo del promedio nacional; la población indígena sobrepasa el promedio nacional, se caracterizan por vivir generalmente en comunidades aisladas y marginadas, el indígena es sujeto de discriminación; en educación, 
el índice de escolaridad media de la población es de 6 años, es decir, nivel primaria; la deserción y eficiencia terminal es muy alta sobre todo en la primaria y secundaria, como causante de este problema y por la poca cobertura educativa se menciona a la dispersión geográfica y el aislamiento en que vive la población; sin embargo, el gasto en la educación por parte del estado es mínima; la esperanza de vida es inferior a la nacional y se cuenta con la menor esperanza de vida al nacer; la mortalidad es debida a las enfermedades infecciosas, parasitarias y asociadas a la desnutrición, la mortalidad infantil es alta en la región; la marginación social es alta y los índices de desarrollo humano son bajos (Plan Puebla Panamá, 2001: 4-51).

La región es muy rica en recursos naturales, ya que en ella se encuentran una gran variedad de suelos, biodiversidad, abundante agua, una extensión costera importante, y se cuenta con yacimientos de hidrocarburos, minerales metálicos y no metálicos y otros recursos naturales aun no utilizados, entre ellos tenemos la energía eólica.

\section{La región del istmo oaxaqueño}

El istmo oaxaqueño se caracteriza por ser una parte estrecha del país y está formada por el distrito 28 Tehuantepec y el distrito 29 Juchitán de Zaragoza; los cuales están conformados con 19 y 22 municipios respectivamente.

La región del istmo oaxaqueño es un lugar destacado por el flujo migratorio de centroamericanos, los cuales utilizan al ferrocarril como medio de transporte para llegar a los Estados Unidos. En el año 2007, en Ciudad Ixtepec se creó la casa del migrante "Hermanos del Camino" dirigida por el Padre Alejandro Solalinde Guerra, coordinador de la Pastoral de Movilidad Humana zona sur pacífico del Episcopado Mexicano. Sin embargo, durante el 2010 se reportó el secuestro masivo de migrantes a la altura de Chahuites, población perteneciente a la región de estudio (Chaca, 2010). Es necesario resaltar que una parte de los ciudadanos de la zona ven a los migrantes como un peligro ya que los vinculan con hechos delictivos como: robos, agresiones físicas y verbales, incluso con asesinatos.

La posición del istmo oaxaqueño contribuye a que subsista una rica diversidad de interpretaciones del mundo y de la historia del hombre desde su pasado, presente y futuro. Los grupos religiosos presentes en la región son masones, testigos de Jehová, mormones, pentecostés, nazarenos, católicos y el sincre- 
tismo religioso local. Sin embargo, la religión que predomina en la zona es la católica.

Un aspecto importante que se debe de resaltar es que se reconoce a Juchitán como el primer municipio del istmo en realizar "la vela gay o vela muxhe", acompañada de su propio convite de flores o regada. Otros municipios que se han unido a esta festividad son el Espinal y Ciudad Ixtepec, donde además realizan sus velas y labradas de cera. Aunque son reconocidos los muxhes en la región persiste la burla o crítica hacia ellos por su conducta y manera de vestir. Se les asocia con actividades como estilistas, cocineros, confeccionistas de ropa, elaboración de manualidades, y adornos para fiestas, en la región consideran a los muxhes como personas muy trabajadoras (Pablo, 2011).

Con respecto al género, se puede decir que el rol de la mujer es importante, ya que desde épocas remotas se ha dedicado al comercio, actividad donde la mano femenina predomina; los hombres por su parte se dedican a actividades primarias, secundarias y en menor medida al comercio.

En la zona del istmo oaxaqueño se encuentra el IV batallón de fuerzas especiales, Grupo Aeromóvil de Fuerzas Especiales (G.A.F.E.S.), en Ciudad Ixtepec, el 13 regimiento de caballería motorizada, la Base Aérea Militar No. 2, ubicada en áreas colindantes con el pueblo de Ixtaltepec, rumbo a la comunidad de Comitancillo.

Las actividades económicas predominantes en la zona son las primarias, destacando entre ellas la agricultura de subsistencia con la siembra del maíz, en los últimos años, se ha sembrado sorgo, ajonjolí etc., existe pesca, pero es de cabotaje; en las actividades secundarias destaca la industria de transformación con la Refinería Ingeniero Antonio Dovalí Jaime, en el municipio de Salina Cruz. Estando así la situación socioeconómica de la región del istmo oaxaqueño la empresa transnacional española Acciona, vio en la región un mercado rentable y redituable en la generación de energías limpias. Esta empresa invierte en los países receptores procurando reactivar el desarrollo local y a su vez invirtiendo en el desarrollo social. Pero cabe la pregunta ¿qué tanto invertirá a nivel local o regional? En general la región del istmo oaxaqueño tiene mucha potencialidad con respecto a la generación de energías limpias, con la utilización de los vientos de la zona. 


\section{Agencia Municipal La Venta}

La Agencia Municipal La Venta pertenece al Municipio de Juchitán de Zaragoza, Oaxaca, México, se instaló en ella el parque eólico Eurus, el cual comprende 2.500 hectáreas y su producción es de 250,5 MW. Dicha infraestructura costó una inversión de 550 millones de dólares y la integran 200 aerogeneradores de 1,5 MW de tecnología. Esta producción tiene como destino las plantas de CEMEX en México, que equivalen al consumo de una población de medio millón de habitantes (ACCIONA, 2010).

EURUS es uno de los mayores parques eólicos del mundo y el segundo en reducción de emisiones registrado ante el Mecanismo de Desarrollo Limpio de las Naciones Unidas (Protocolo de Kyoto).

El proyecto generó más de 850 empleos directos en la zona durante la fase de construcción y está generando una derrama económica anual de más de 20 millones de pesos en la región (http://www.3ersector.org.mx, 2011).

Según los ejecutivos de CEMEX el parque eólico Eurus será el más grande en América Latina y su término estará integrado por 200 aerogeneradores (http://www.evwind.es, 2009). La empresa ACCIONA está construyendo además tres parques eólicos adicionales en el estado de Oaxaca, que suman una potencia conjunta de $306 \mathrm{MW}$. Con una inversión superior a los 600 millones de dólares, se dispondrá de 204 aerogeneradores AW-1500 de tecnología ACCIONA Windpower (ACCIONA, 2010).

La Comisión Federal de Electricidad de México (CFE) adjudicó a Iberdrola Renovables la construcción del parque eólico La Venta III; el parque eólico se ubica en el Municipio de Santo Domingo Ingenio, tendrá una potencia de 103 MW. Se instarán 121 aerogeneradores del modelo G52 de Gamesa Eólica, de $850 \mathrm{KW}$ de potencia y 44 metros de altura. Se calcula que su producción suministrara a cerca de 200.000 personas, con lo cual contribuirá al desarrollo económico del estado (http://www.evwind.es, 2009).

Sin embargo, después de trabajar algún tiempo las empresas españolas en la zona del istmo oaxaqueño se muestran algunos descontentos sociales, por ejemplo: Según el diario el Sur, desde su llegada al istmo ACCIONA ha realizado prácticas no éticas y ha corrompido a una serie de autoridades tanto Estatales, municipales y federales. 
La española ACCIONA sin escrúpulo alguno viola los derechos de ejidatarios al no cubrirles las afectaciones que por sus proyectos realiza en el ejido de La Venta, según el poblador Juan Marcos Ayala. Ejidatarios de esta comunidad sufren de la prepotencia y el desinterés de los directivos para cubrir las afectaciones que se realizaron en el proyecto Euros donde tienen ya instalada su infraestructura, indemnización que se ha venido exigiendo en múltiples ocasiones sin que la comuna tenga respuesta favorable por parte del director general de esta multinacional en México,

Miguel Ángel Alonso Rubio, a cambio se ha instrumentado como estrategia para evadir el pago, negociar con prebendas ridículas en forma individual con los posesionarios de las tierras evitando dialogar en asamblea, máxima autoridad del ejido, como lo marca la ley, situación que ha llegado a dividir las posturas hacía el interior del propio ejido, misma que podría derivar en una desestabilización social que llevaría a que el ejido en las próximas semanas determine la suspensión definitiva de los proyectos Oaxaca III, y Oaxaca IV que actualmente esta empresa desarrolla en la región.

...entre las prácticas más comunes que realiza ACCIONA en el istmo está en que construye sus líneas de trasmisión en terrenos contratados por otras empresas, y registra contratos de terrenos ya foliados con anterioridad en el registro público de la propiedad por otros proyectos, como se desprende de un informe interno elaborado por el gobierno del Estado que obra en poder de este diario (El Sur, 2010: 4).

Con la construcción de los aerogeneradores en la Agencia Municipal La Venta, ha conducido a que la localidad sea conocida nivel mundial, es decir, no sólo la agencia, sino el región del istmo oaxaqueño, ya que ha generado la interdependencia entre las empresas por el flujo de mercancías y personas, capital, conocimiento e información; aunque quedan áreas rezagadas, como el mejoramiento del transporte; el drenaje, el servicio de recolección de basura, etc. Otro fenómeno que se ha acentuado en la región es la privatización de las tierras y con ello la desintegración de las tierras comunales, y esto a su vez a generado una especialización en algunos productos, como es el caso del trigo, lo que ha contribuido a la jerarquización de los territorios de la región. En los cuales se demuestra la creciente desigualdad social que se da en el istmo de oaxaqueño. Por otra parte, el pago del trabajo y las oportunidades de este, que son pocas en la región, repercute en la pugna por el empleo. Creando un ambiente favorable para que las empresas no respeten las normas laborables del país, es 
decir, una parte del personal tiene que trabajar en turnos diferentes durante el mes. Con la inversión de las trasnacionales llegan otras empresas que controlan el comercio; como es el caso de Bodega Aurrera y Soriana. Es decir, la franquicia de Aurrera se esta adueñando de la distribución, comercio y ocio de la zona. Sin duda alguna podemos señalar que están homogenizando la región en sus espacios económicos, sociales, políticos y culturales de forma sutil. Lo cual conlleva a una transformación social, económica, política y cultural de la región del istmo oaxaqueño hacia un mercado global.

\section{Conclusiones}

El territorio es un producto social en la cual se debe de resaltar la cooperación entre los diferentes actores que inciden en las comunidades, como son: la administración pública local, las empresas privadas, las organizaciones no gubernamentales, instituciones educativas etc., por el bienestar del desarrollo a escala local y regional. Las decisiones que se realicen deben de ser conforme a las necesidades de los ciudadanos locales y regionales, no deben de predominar sólo los intereses de las trasnacionales o de los grupos de empresas. La inversión que se realiza en la zona debe de responder a necesidades colectivas, es decir, se debe de considerar la participación a la sociedad en conjunto, con el fin de integrarlos al desarrollo local, regional, nacional e internacional, con el fin de disminuir las desigualdades sociales en diferentes escalas y de esta manera evitar la fragmentación del territorio. La inversión extranjera siempre debe de estar bajo la supervisión del Estado, es decir, el Estado será el coordinador de las políticas públicas en todos los niveles, ninguna organización o empresa debe estar sobre él y siempre deben de dominar los intereses nacionales y de la población afectada. El Estado debe de aceptar la diversidad de actores, garantizando la participación de los ciudadanos para aminorar las desigualdades sociales en ciertas regiones, sobre todo en aquellas que el Estado las había "abandonado" fomentando una participación más activas en las toma de decisiones, locales, regionales, estatales y federales, como debe de ser en la región del istmo oaxaqueño, porque si no se corre el peligro de fragmentar aun más la región del istmo oaxaqueño. 


\section{Bibliografía}

\section{ACCIONA}

2010 México instala un aerogenerador de ACCIONA en la Cumbre Mundial del Clima de Cancún, en línea:

http://www.acciona.es/noticias/mexico-instala-un-aerogenerador-de-acciona-en-la-cumbre-mundial-del-clima-de-cancun, fecha de acceso 07 de diciembre.

BASSOLS BATALLA, Ángel

1980 Geografía socioeconómica de México. Aspectos físicos y económicos por regiones. México: Ed. Trillas México.

CHACA, Roselia

2010 Continúan las amenazas contra el padre Solalinde, en wwwn.noticias.net. $\mathrm{mx}$, fecha de consulta 05.01.2011.

DABAT Alejandro

2002 "Globalización, capitalismo actual y nueva configuración espacial del mundo”, en: Jorge Basave. Globalización y alternativas incluyentes para el siglo XXI. México: Universidad Nacional Autónoma de México.

El Sur, sábado 04 de diciembre de 2010. Diario independiente del Istmo, Juchitán de Zaragoza, Oaxaca, México.

LORA Marcela

2010 La 'euromanisfestación' convoca a unas 90.000 personas en Bruselas. España en http://www.elmundo.es/mundodinero/2010/09/29/econo$\underline{\mathrm{mia} / 1285765120 . \mathrm{html} \text {, fecha de consulta 09.09.2010. }}$

ROMERO Juan (coordinador) y Joan Nogué

2004 Geografía Humana. Madrid, España: Ariel.

STERLING PÉREZ, Bessy Elvia y Eduardo Villanueva Herrera

2005 Geografía Económica. México.

Plan Puebla Panamá

2001 México.

Pablo Manuel Sánchez Estudillo, Licenciado en Administración Pública, entrevista realizada el 05 de enero de 2011.

http://www.3ersector.org.mx/index2.php?option $=$ com content\&do $\mathrm{pdf}=1 \& \mathrm{id}=15067$, fecha de acceso 16 de enero del 2011

http://www.evwind.es/noticias.php?id not=347, Adjudicado un parque eólico en Oaxaca, México, de 101 MW., fecha de acceso 14 de mayo de 2009.

Envío 8 de agosto de 2012 - Fecha de aceptación 5 de diciembre de 2012. 